\title{
One Pot Green Synthesis of Colloidal Silver Nanocrystals Using the Ventilago maderaspatana Leaf Extract: Acute Toxicity on Malaria, Zika Virus and Filariasis Mosquito Vectors
}

\author{
Raja Mohamed Sait Thameem Azarudeen ${ }^{1}$. \\ Marimuthu Govindarajan ${ }^{2}$ - Mashael Marzouq AIShebly ${ }^{3}$. \\ Fatma Saeed AlQahtani ${ }^{4}$ - Abubucker Amsath ${ }^{1}$. \\ Giovanni Benelli ${ }^{5}$
}

Received: 3 October 2016/Published online: 18 October 2016

(C) Springer Science+Business Media New York 2016

\begin{abstract}
Mosquitoes act as a vector for most of the life-threatening diseases. The green synthesis of eco-friendly metal nanoparticles is a fast-growing branch of current nanoscience with a number of biomedical and entomological implications. Here, we have synthesized silver nanoparticles (AgNPs) by using a poorly studied Indian plant, Ventilago maderaspatana. The results recorded from UV-Visible spectrophotometry, Fourier transform infrared spectroscopy (FTIR), X-ray diffraction analysis (XRD), atomic force microscopy (AFM), scanning electron microscopy (SEM) and transmission electron microscopy (TEM) confirmed the quick synthesis of AgNPs. The toxic activity of $V$. maderaspatana leaf extract and biosynthesized AgNPs was evaluated against the malaria vector Anopheles stephensi, the Zika virus vector Aedes aegypti and the filariasis vector Culex quinquefasciatus. Compared to the leaf aqueous extract, AgNPs showed higher toxicity against A. stephensi, A. aegypti, and C. quinquefasciatus with $\mathrm{LC}_{50}$ values of 24.89 , 26.92 and $29.24 \mu \mathrm{g} / \mathrm{mL}$, respectively. A single treatment with AgNPs tested at 120,
\end{abstract}

Marimuthu Govindarajan

drgovind1979@gmail.com

$\bowtie$ Giovanni Benelli

benelli.giovanni@gmail.com

1 Department of Zoology, Khadir Mohideen College, Adirampattinam, Tamil Nadu 614701, India

2 Unit of Vector Control, Phytochemistry and Nanotechnology, Department of Zoology,

Annamalai University, Annamalainagar, Tamil Nadu 608 002, India

3 Department of Obstetrics and Gynecology, College of Medicine, King Saud University and King Saud University Medical City, Riyadh, Saudi Arabia

4 Hematology Unit, Department of Pathology, College of Medicine, King Saud University and King Saud University Medical City, Riyadh, Saudi Arabia

5 Department of Agriculture, Food and Environment, University of Pisa, via del Borghetto 80, 56124 Pisa, Italy 
150 and $180 \mu \mathrm{g} / \mathrm{mL}$ led to no egg hatchability. In adulticidal experiments, the maximum efficacy was observed on A. stephensi $\left(\mathrm{LD}_{50}=41.19 \mu \mathrm{g} / \mathrm{mL}\right)$, followed by A. aegypti $\left(\mathrm{LD}_{50}=44.85 \mu \mathrm{g} / \mathrm{mL}\right)$ and C. quinquefasciatus $\left(\mathrm{LD}_{50}=48.94 \mu \mathrm{g} /\right.$ $\mathrm{mL}$ ), respectively. V. maderaspatana extract and green fabricated AgNPs were found safer to non-target aquatic biocontrol organisms Anisops bouvieri, Diplonychus indicus and Gambusia affinis, with $\mathrm{LC}_{50}$ ranging from 1673 to $41,854 \mu \mathrm{g} / \mathrm{ml}$.

Keywords Biofabrication - Silver nanoparticles - SEM, TEM, AFM - Culicidae · Mosquito-borne diseases

\section{Introduction}

Mosquitoes transmit more diseases than any other group of arthropods affecting millions of people throughout the world. Mosquito vectors are solely responsible for transmitting diseases such as malaria, dengue, chikungunya, Japanese encephalitis, lymphatic filariasis and, very recently, Zika virus [1]. Vector control is an essential requirement in the management of epidemic diseases that are transmitted by mosquitoes. Notably, the excessive use of synthetic pesticides causes emergence of resistance in treated pests and also lead to harmful effect on non-target organisms [2]. This has required an urgent search for development of new and improved mosquito control methods that are cheap, effective and safe for human health and the environment [3-7].

Noble metal nanoparticles have received attention over the last few years, as they can be used in medicine, biology, material science, physics, and chemistry [8]. Among the several noble metal nanoparticles, silver nanoparticles (AgNPs) have attracted special attention due to their properties, which include favorable electrical conductivity, chemical stability, catalytic and antibacterial activity $[9,10]$. The green synthesis of AgNPs has been accomplished using plants, microorganisms, and biopolymers [9]. The use of plant-borne products for nanoparticle synthesis offers a wide range of benefits over other biological synthesis methods because it does not require the maintenance of cell cultures and incorporates support for the large-scale synthesis of nanoparticles [11]. The extracellular nanoparticle synthesis, which utilizes extracts different plant parts, is often inexpensive due to easier downstream processing [12-16].

Nowadays, a growing number of plants have been screened successfully for nanosynthesis of silver-based mosquitocides, including Sida acuta [17], Barleria cristata [18], Chomelia asiatica [19], Gmelina asiatica [20], Feronia elephantum [21], and Heliotropium indicum [22]. Phyto-synthesized AgNPs have been recently proposed as effective mosquito larvicides, and are gaining importance over synthetic chemical pesticides because of their reduced harmful effects to nontargeted species and novelty in the mechanism(s) of action [12-14, 23, 24].

Ventilago maderaspatana is a medicinal herb belonging to family Rhamnaceae. It is distributed in Forests of low elevations-South Greece, India, Indonesia, Myanmar, Sri-Lanka. It is commonly known as red creeper. This plant is a woody climber. Traditionally, the root bark of $V$. maderaspatana is used as a carminative, 
stomachic, vitiated conditions of kapha, dyspepsia, colic flatulence, erysipelas, leprosy, scabies, and pruritus. The powdered stem bark mixed with gingerly oil is applied externally to treat skin diseases and itch [25]. Apart from these, antifeedant activity of $V$. maderaspatana on insects was also reported [26]. The phytochemical reports on the root bark of $V$. maderaspatana show the presence of various anthraquinones, including ventinone-A.B, chrysophanol, physcion, emodin, islandicin, xanthorin and xanthorin-5-methyl ether [27]. The plant extracts act as an antibacterial agent [28], and also shows anti-denaturation and antioxidant properties [29]. The stem bark of $V$. maderaspatana was found to possess anti inflammatory and anticancer activities [30].

In this research, we proposed a cheap and rapid method of biosynthesis of polydispersed AgNPs using the aqueous leaf extract of $V$. maderaspatana. Bio-reduced AgNPs were characterized by UV-Vis spectrophotometry, Fourier transform infrared spectroscopy (FTIR), X-ray diffraction analysis (XRD), atomic force microscopy (AFM), scanning electron microscopy (SEM) and transmission electron microscopy (TEM). The acute toxicity of $V$. maderaspatana leaf extract and biosynthesized AgNPs was evaluated against the eggs, larvae and adults of malaria vector A. stephensi, the Zika virus and dengue vector A. aegypti and the filariasis vector $C$. quinquefasciatus. Furthermore, we evaluated the biotoxicity of $V$. maderaspatana aqueous extract and green-synthesized AgNPs on three non-target aquatic biocontrol organisms of mosquito young instars, Anisops bouvieri, Diplonychus indicus, and Gambusia affinis.

\section{Materials and Methods}

\section{Materials}

Silver nitrate was procured from Merck, India. The glassware was acid-washed thoroughly and then rinsed with Millipore Milli-Q water. Healthy and fresh leaves of $V$. maderaspatana were collected from Nilgiris, Western Ghats $\left(11^{\circ} 10^{\prime} \mathrm{N}\right.$ to $11^{\circ} 45^{\prime} \mathrm{N}$ latitude and $76^{\circ} 14^{\prime} \mathrm{E}$ to $77^{\circ} 2^{\prime} \mathrm{E}$ longitude), Tamil Nadu State, India. The identity was confirmed at the Department of Botany, Annamalai University, Annamalai Nagar, Tamil Nadu. Voucher specimens were numbered and kept in our laboratory and are available upon request.

\section{Preparation of Plant Extract}

Leaves of $V$. maderaspatana (Fig. 1) were dried in the shade and ground to fine powder in an electric grinder. Aqueous extract was prepared by mixing $50 \mathrm{~g}$ of dried leaf powder with $500 \mathrm{~mL}$ of water (boiled and cooled distilled water) with constant stirring on a magnetic stirrer. The suspension of dried leaf powder in water was left for $3 \mathrm{~h}$ and filtered through Whatman $\mathrm{n}$. 1 filter paper and the aqueous filtrate were stored in an amber-colored airtight bottle at $10{ }^{\circ} \mathrm{C}$ temperature until testing. 


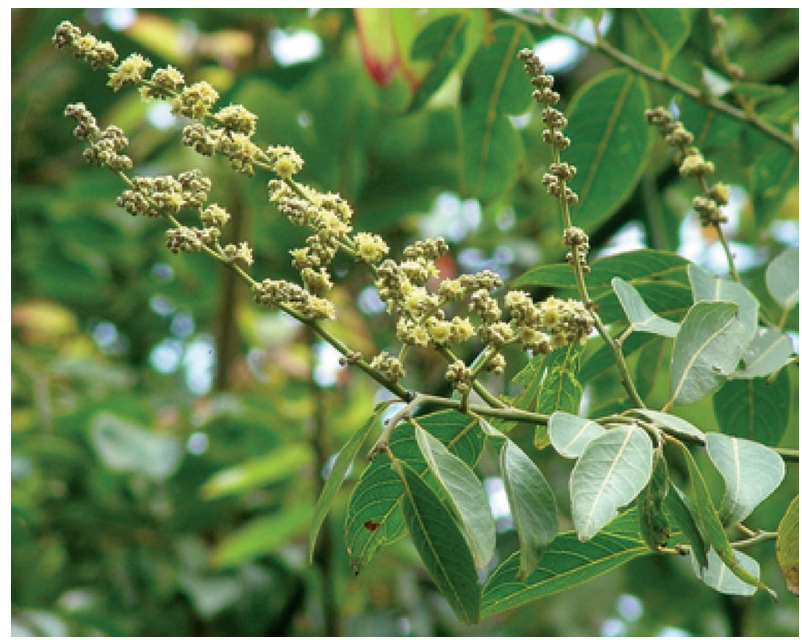

Fig. 1 Ventilago maderaspatana (Rhamnaceae)

\section{Green Synthesis of Silver Nanoparticles}

Ten grams of thoroughly washed and finely cut leaves were added in a $300-\mathrm{mL}$ Erlenmeyer flask along with $100 \mathrm{~mL}$ of sterilized double-distilled water, the mixture was boiled for $5 \mathrm{~min}$ before finally decanting it. The colloidal extract was filtered with Whatman filter paper n. 1 , stored at $-15^{\circ} \mathrm{C}$ and tested within a week. The filtrate was treated with aqueous $1 \mathrm{mM} \mathrm{AgNO} 3$ (21.2 $\mathrm{mg}$ of $\mathrm{AgNO}_{3}$ powder in $125 \mathrm{~mL}$ of Milli-Q water) solution in an Erlenmeyer flask and incubated at room temperature. Eighty-eight milliliters of an aqueous solution of $1 \mathrm{mM}$ silver nitrate was reduced using $12 \mathrm{~mL}$ of leaf extract at room temperature for $10 \mathrm{~min}$, resulting in a brown-yellow solution indicating the formation of AgNPs.

\section{Biophysical Characterization of Silver Nanoparticles}

The bioreduction of $\mathrm{Ag}^{+}$ions was monitored using a UV-Vis spectrophotometer (UV-160v, Shimadzu, Japan). The analysis of size, morphology, agglomeration pattern and dispersed nature of Ag NPs were performed using atomic force microscopy (Agilent Technologies AFM- 5500), scanning electron microscopy (Hitachi S3000 H SEM) and transmission electron microscopy (TEM Technite 10 Philips). The purified AgNPs were examined for the presence of biomolecules using FTIR spectroscopy (Thermo Scientific Nicolet 380 FT-IR Spectrometer) KBr pellets and crystalline AgNPs were determined by XRD analysis.

\section{Mosquito Rearing}

Following the method by Govindarajan and Benelli [31], laboratory-bred pathogenfree strains of mosquitoes were reared in the vector control laboratory, Department of Zoology, Annamalai University. At the time of adult feeding, these mosquitoes 
were 3-4 days old after emergences (maintained on raisins and water) and were starved for $12 \mathrm{~h}$ before feeding. Each time, 500 mosquitoes per cage were fed on blood using a feeding unit fitted with Parafilm as membrane for $4 \mathrm{~h}$. A. aegypti feeding was done from 12 noon to 4.00 p.m. and $A$. stephensi and $C$. quinquefasciatus were fed during 6.00 p.m. to 10.00 p.m. A membrane feeder with the bottom end fitted with Parafilm was placed with $2.0 \mathrm{ml}$ of the blood sample (obtained from a slaughter house by collecting in a heparinized vial and stored at $4{ }^{\circ} \mathrm{C}$ ) and kept over a netted cage of mosquitoes. The blood was stirred continuously using an automated stirring device, and a constant temperature of $37^{\circ} \mathrm{C}$ were maintained using a water jacket circulating system. After feeding, the fully engorged females were separated and maintained on raisins. Mosquitoes were held at $28 \pm 2{ }^{\circ} \mathrm{C}, 70-85 \%$ relative humidity, with a photo period of 12 -h light and 12-h dark.

\section{Larvicidal Activity}

The larvicidal activity of the aqueous crude extract and AgNPs from $V$. maderaspatana was evaluated according to WHO [32]. The aqueous extract was tested at 120, 240, 360, 480 and $600 \mathrm{~g} \mathrm{~mL}^{-1}$ concentrations. AgNPs were tested at $12,24,36,48$ and $60 \mu \mathrm{g} \mathrm{mL}^{-1}$ concentrations. Twenty late III instar larvae were introduced into a 500-mL glass beaker containing $250 \mathrm{~mL}$ of dechlorinated water, plus the desired concentrations of leaf extract or AgNPs. For each concentration, five replicates were performed. Larval mortality was recorded at $24 \mathrm{~h}$ after exposure, during which no food was given to the larvae. Each test included a set control groups (i.e. silver nitrate and distilled water, Govindarajan and Benelli [31] with five replicates for each individual concentration.

\section{Ovicidal Activity}

To evaluate the ovicidal potential of the leaf axtract and AgNPs, the method of $\mathrm{Su}$ and Mulla [33] with slight modification by Govindarajan et al. [34] was followed. Eggs were collected from vector control laboratory, Department of Zoology, Annamalai University. The aqueous leaf extracts and silver nanoparticle were to achieve various concentrations ranging from 100 to $600 \mu \mathrm{g} / \mathrm{ml}$ and 30 to $180 \mu \mathrm{g} /$ $\mathrm{mL}$, respectively. Eggs of these mosquito species $(n=100$ for $0-6,6-12$ and 12-18 h old egg rafts) were exposed to each concentration of leaf aqueous extract and AgNPs. After treatment, the eggs from each concentration were individually transferred to distilled water cups for hatching assessment after counting the eggs under a photomicroscope (Leica, Germany). Each experiment was replicated six times along with untreated controls. The hatch rates were assessed $48 \mathrm{~h}$ posttreatment by the following formula.

$$
\text { Egg hatchability }(\%)=\frac{\text { Number of hatched larvae }}{\text { Total number of eggs }} \times 100
$$




\section{Adulticidal Activity}

Adulticidal bioassays were performed following the method by WHO [35]. Based on the wide range and narrow range tests, aqueous crude extract was tested at 150 , 300, 450, 600 and $750 \mu \mathrm{g} \mathrm{mL}^{-1}$ concentrations, and AgNPs were tested at 20, 40, 60, 80, and $100 \mu \mathrm{g} \mathrm{mL}^{-1}$ concentrations. Aqueous crude extract and AgNPs were applied on Whatman n. 1 filter papers (size $12 \times 15 \mathrm{~cm}$ ). Control papers were treated with silver nitrate and distilled water. Twenty female mosquitoes were collected and gently transferred into a plastic holding tube. The mosquitoes were allowed to acclimatize in the holding tube for $1 \mathrm{~h}$ and then exposed to test paper for $1 \mathrm{~h}$. At the end of exposure period, the mosquitoes were transferred back to the holding tube and kept for 24-h recovery period. A pad of cotton soaked with $10 \%$ glucose solution was placed on the mesh screen. Each test included a set control groups (silver nitrate and distilled water) with five replicates for each individual concentration.

\section{Biotoxicity on Non-target Biocontrol Agents}

The acute toxicity of nanoparticles on non-target biocontrol agents was assessed following the method by Sivagnaname and Kalyanasundaram [36] slightly modified by Govindarajan and Benelli [37]. The effect of aqueous extract and AgNPs of the potential plant was tested against non-target biocontrol agents A. bouvieri, $D$. indicus, and G. affinis. The species were field collected and separately maintained in cement tanks (85 cm diameter and $30 \mathrm{~cm}$ depth) containing water at $27 \pm 3{ }^{\circ} \mathrm{C}$ and external relative humidity $85 \%$. The $V$. madrasapatna aqueous extract and AgNPs were evaluated at concentrations of even 50 times higher the $\mathrm{LC}_{50}$ dose calculated on mosquito larvae. Ten replicates were performed for each concentration, along with four replicates of untreated controls. The non-target organisms were observed for mortality and other abnormalities such as sluggishness and reduced swimming activity after $48 \mathrm{~h}$ exposure. The exposed non-target organisms were also monitored for ten days to understand the post treatment effect of the treatment on survival and swimming activity.

\section{Data Analysis}

All mortality data were subjected to probit analysis. $\mathrm{LC}_{50}$ and $\mathrm{LC}_{90}$ were calculated using the method by Finney [38]. In experiments evaluating biotoxicity on nontarget biocontrol agents, the Suitability Index (SI) was calculated for each nontarget species using the following formula [39].

$$
\mathrm{SI}=\frac{\mathrm{LC}_{50} \text { of non }- \text { target organisms }}{\mathrm{LC}_{50} \text { of target vector species }}
$$

All data were analyzed using the SPSS Statistical Software Package version 16.0. A probability level of $\mathrm{P}<0.05$ was used for the significance of differences between values. 


\section{Results and Discussion}

\section{Green Synthesis and Characterization of AgNPs}

After incubation with silver nitrate in a dark room, the pale yellow colloidal aqueous extract turned into a dark brown suspension, which indicated AgNPs biosynthesis (Fig. 2a). V. maderaspatana-synthesized AgNPs exhibited a brown color, probably due to excitation of surface plasmon vibrations [18, 31, 37]. The preliminary AgNPs synthesis reaction was monitored by UV-Vis spectra scanning of the cell-free extract which had been introduced with $\mathrm{AgNO}_{3}$. After 180 min of incubation the reaction mixture showed a broad spectrum of peak at $411 \mathrm{~nm}$ which is the characteristic of AgNPs (Fig. 2b). The peak intensities increased at 5-20 min,

(a)

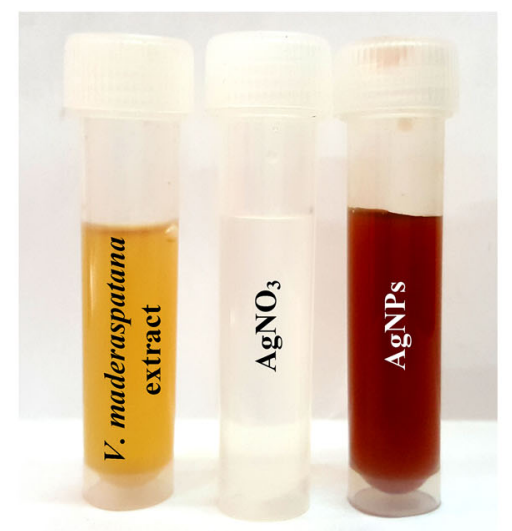

(b)

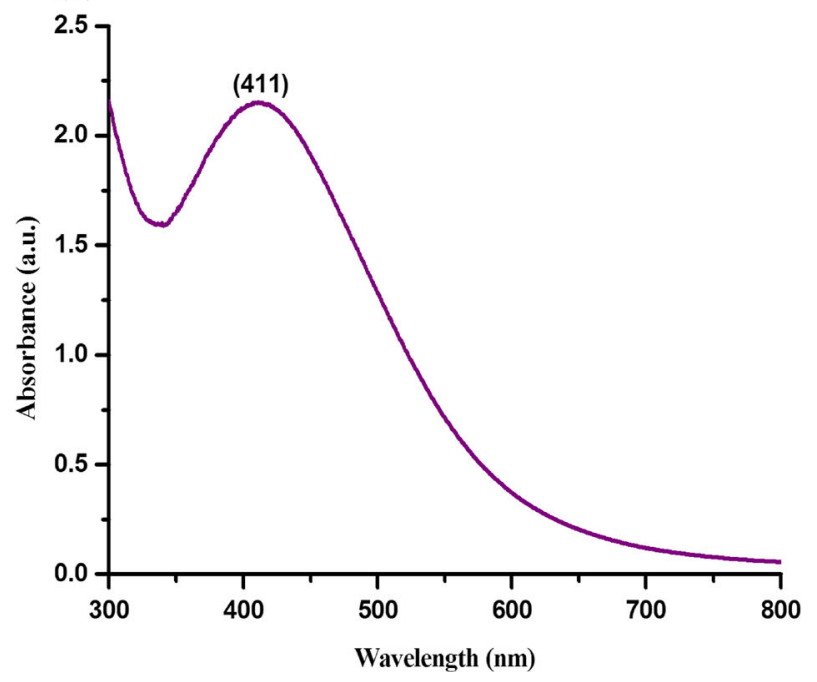

Fig. 2 a Color intensity of Ventilago maderaspatana aqueous extract before and after the reduction of silver nitrate $(1 \mathrm{mM})$. The color change indicates $\mathrm{Ag}^{+}$reduction to elemental nanosilver (Ag NPs). b UV-Visible spectrum of silver nanoparticles after $180 \mathrm{~min}$ from the reaction (Color figure online) 
which indicates growth as well as the formation of AgNPs in the reaction mixture. In the control sample of cell-free extract the peak was observed at $280 \mathrm{~nm}$, which is characteristic of the biomolecules [40]. Interestingly there is no precipitation observed for synthesized AgNPs solution over 90 days of storage at $37^{\circ} \mathrm{C}$ and the sample was scanned at the same wavelength. The resultant spectrum showed no considerable change in the peak position compared with earlier observation of SPR peak at $411 \mathrm{~nm}$, which indicated the biogenic AgNPs were highly stable after several weeks [41].

The crystalline structure of biogenic AgNPs was confirmed by XRD. The diffraction spectrum of AgNPs showed face centred cubic (FCC) crystalline nature of four intense peaks were observed at (Fig. 3) $37.62^{\circ}, 44.25^{\circ}, 64.74^{\circ}$ and $77.93^{\circ} 2 \theta$ corresponding to plane values of (111), (200), (220) and (311) reflections and the face-centered cubic structure of metallic silver, respectively [42].

The FTIR spectrum of the cell-free extract alone showed five distinct peaks at the range of $3626,3381,1567,1384$, and $1077 \mathrm{~cm}^{-1}$ (Fig. 4). The band at 3626, $3381 \mathrm{~cm}^{-1}$ was referred as the strong stretching vibrations of the $\mathrm{OH}-$ functional group [43]. The peak at $1567 \mathrm{~cm}^{-1}$ was probably due to the symmetric stretching vibrations of the COO-functional group [44], and $1384 \mathrm{~cm}^{-1}$ may be assigned to the amide functional groups present in the cell free supernatant [45]. The band at $1077 \mathrm{~cm}^{-1}$ could be attributed to the $\mathrm{C}-\mathrm{O}-$ stretching vibrations [46]. To compare the IR spectrum of the cell free supernatant and synthesized AgNPs, the major shifts were observed in the hydroxyl and carboxyl functional groups of protein which may be responsible for synthesis of AgNPs.

AFM is a primary tool for analyzing size, shape, agglomeration pattern and offers visualizations of three-dimensional views of the nanoparticles unlike the electron microscopes. It has an advantage over combination of high resolution, samples does

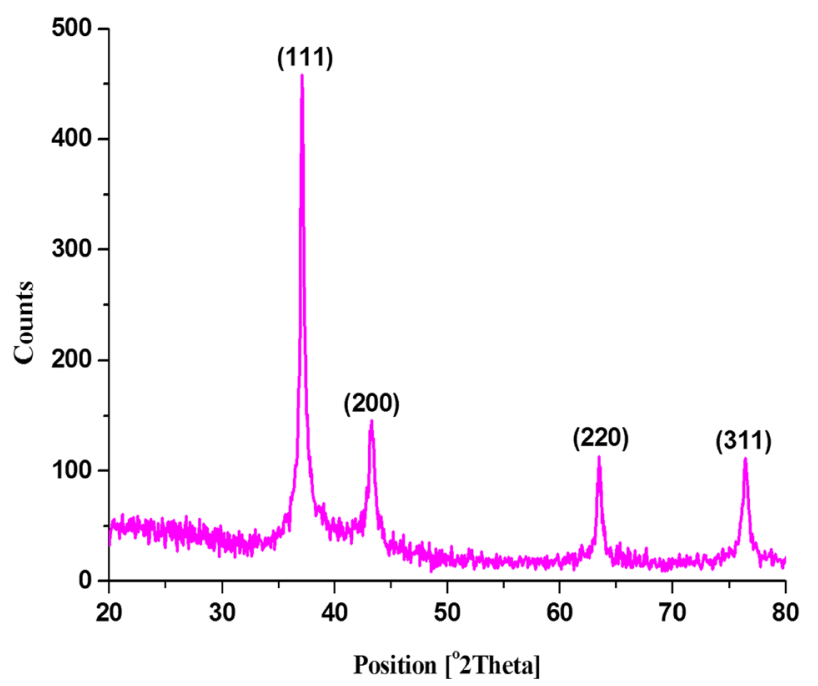

Fig. 3 XRD pattern of silver nanoparticles biofabricated using the Ventilago maderaspatana aqueous leaf extract 


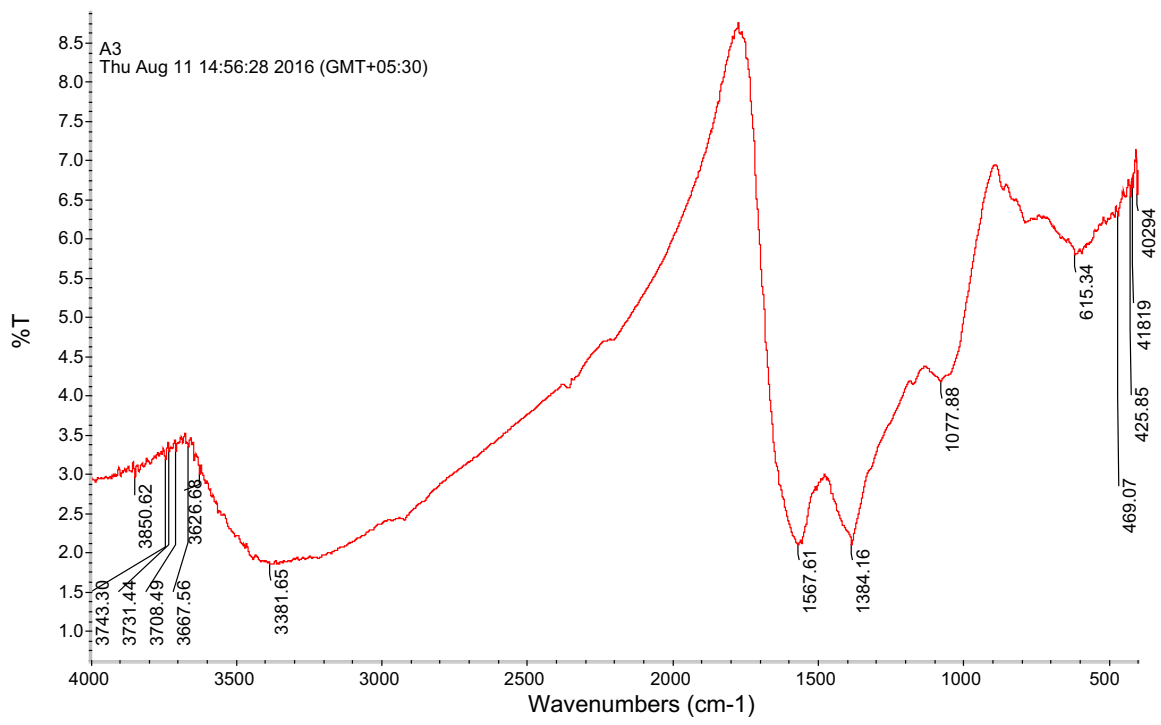

Fig. 4 FTIR spectrum of silver nanoparticles biofabricated using the Ventilago maderaspatana aqueous leaf extract

not have to be conductive and does not require the high-pressure vacuum conditions. $2.5 \mu \mathrm{m}$ resolution studies of biologically synthesized AgNPs with AFM reveal the particles are polydispersed, spherical in shape, having the main size ranging from 1 to $6 \mathrm{~nm}$ and there is no agglomeration observed between the particles (Fig. 5a). Raw data obtained from this AFM microscope is treated with a specially designed image processing software (NOVA-TX) to further exploit the 3D image of nanoparticles (Fig. 5b). The average particle size obtained from the corresponding diameter distribution was 4.6-5 nm (Fig. 5c, d).

SEM analysis was performed in order to investigate the morphology and size distribution of AgNPs (Fig. 6). SEM showed that the morphology of AgNPs is mostly spherical, in agreement with the shape of SPR band in the UV-Vis spectrum. The average particle size measured from the SEM images was slightly higher if compared to AFM results, reaching $60 \mathrm{~nm}$. Figure 7 reports the EDX profile, showing a strong Ag signal along with other peaks, which may be originated from biomolecules that were bound to the surface of AgNPs. Metallic AgNPs generally show typical absorption peak approximately at $3 \mathrm{keV}$ due to surface plasmon resonance [47]. TEM micrograph confirms the presence of poly-dispersed AgNPs, showing fine configuration of crystalline, spherical AgNPs, with main size ranging between 15 and $20 \mathrm{~nm}$ (Fig. 8), see also [48].

\section{Acute Toxicity Against Mosquito Larvae, Egg and Adult}

Both the V. maderaspatana leaf extract and green-fabricated AgNPs showed dose dependent larvicidal effect against the three tested mosquito species (Table 1). Compared to the leaf aqueous extract, biosynthesized AgNPs showed higher 
Fig. 5 AFM micrograph of silver nanoparticles biofabricated using the Ventilago maderaspatana extract a $2.5 \mu \mathrm{m}$ resolution studies 0 to $6 \mathrm{~nm}$ size, spherical shaped, polydispersed particles, b 3D image of $\mathrm{Ag}$ nanoparticles analyzed by NOVA-TX software, c histogram showing the particle size distribution, d line graph showing the size distribution of green-synthesized Ag nanoparticles

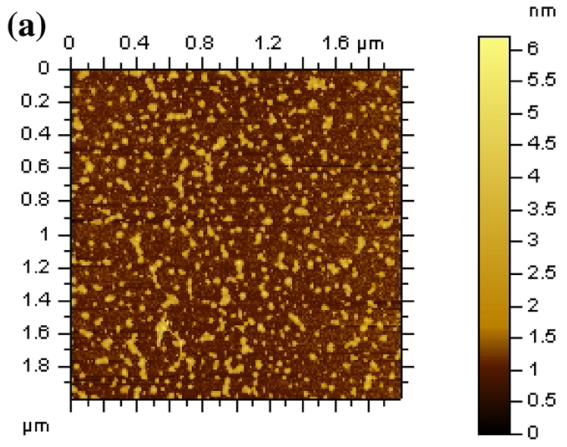

(b)

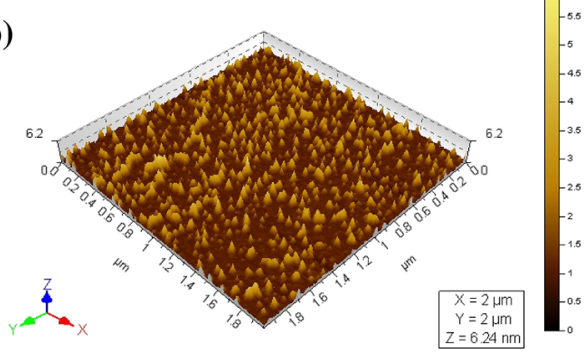

(c)

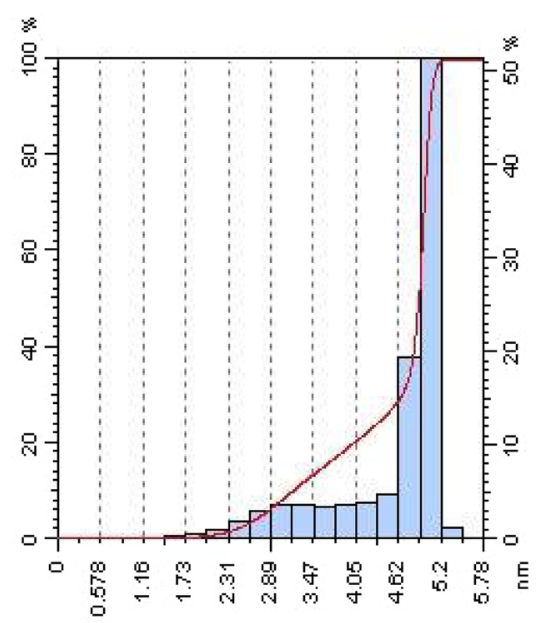

(d)

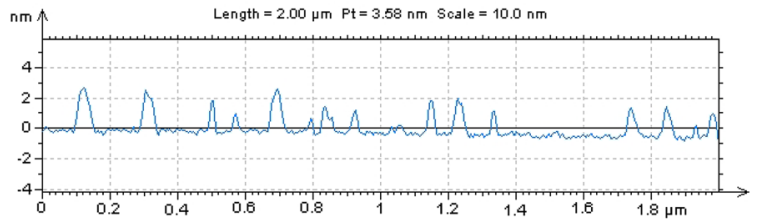




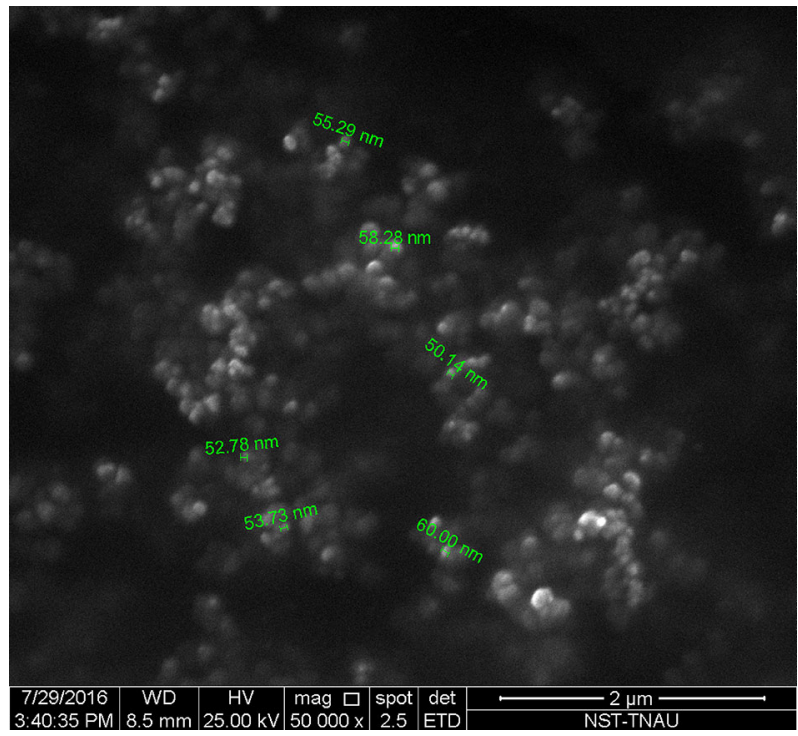

Fig. 6 Scanning electron microscopy (SEM) of Ventilago maderaspatana-fabricated silver nanoparticles

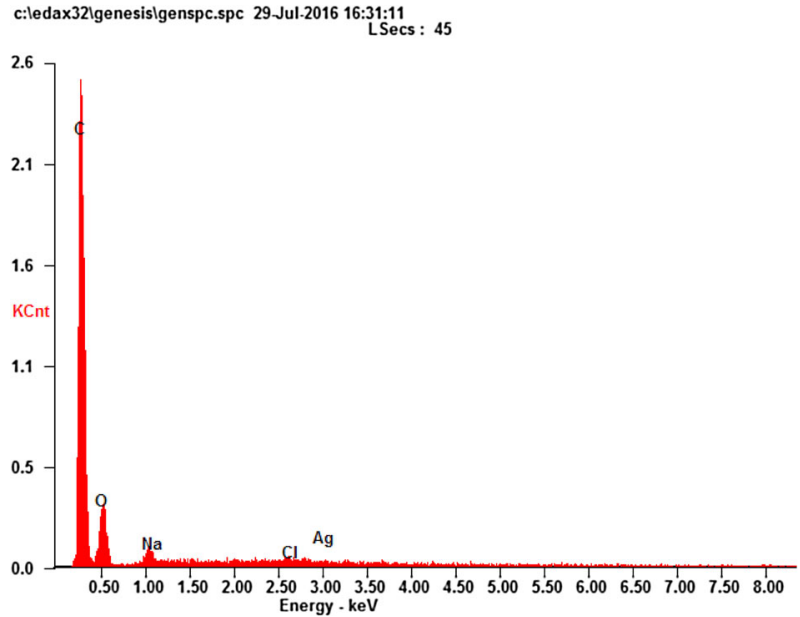

Fig. 7 Energy dispersive X-ray (EDX) spectrum of Ventilago maderaspatana-synthesized silver nanoparticles showing presence of different phyto-elements as capping agents

toxicity against $A$. stephensi, $A$. aegypti and $C$. quinquefasciatus with $\mathrm{LC}_{50}$ values of 24.89, 26.92 and $29.24 \mu \mathrm{g} / \mathrm{mL}$, respectively (Table 2). Furthermore, biosynthesized AgNPs showed enhanced larvicidal effect even at lower concentrations compare to plant derivatives alone, which denotes that AgNPs potentially increases the bioactivity of plant products. 


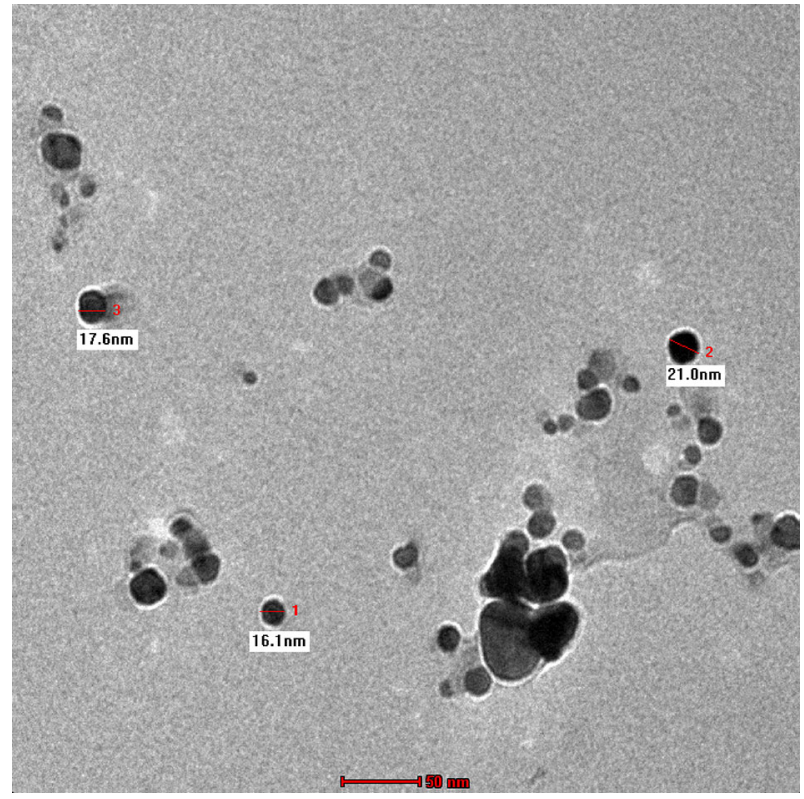

Fig. 8 Trasmission electron microscopy (TEM) of silver nanoparticles biofabricated using the Ventilago maderaspatana aqueous leaf extract

V. maderaspatana aqueous leaf extract and AgNPs exerted $100 \%$ mortality (zero hatchability) when tested at 400, 500, 600 and $120,150,180 \mu \mathrm{g} / \mathrm{mL}$, respectively. Control eggs showed $100 \%$ egg hatchability (Tables 3, 4).

The results of the adulticidal activity of aqueous crude extract and synthesized AgNPs against the adult of A. stephensi, A. aegypti, and C. quinquefasciatus are presented in Tables 5 and 6 . Considerable mortality was evident after the treatment of $V$. maderaspatana for all three important vector mosquitoes. At higher concentrations, the adult showed restless movement for some times with abnormal wagging and then died. The rates of mortality were directly proportional to concentration. The maximum efficacy was observed in green synthesized AgNPs against the adult of $A$. stephensi $\left(\mathrm{LD}_{50}=41.19 \mu \mathrm{g} / \mathrm{mL}\right)$, followed by $A$. aegypti $\left(\mathrm{LD}_{50}=44.85 \mu \mathrm{g} / \mathrm{mL}\right)$, and $C$. quinquefasciatus $\left(\mathrm{LD}_{50}=48.94 \mu \mathrm{g} / \mathrm{mL}\right)$ respectively.

Recently a growing number of plants have been explored for the green synthesis of mosquitocidal AgNPs, and it has been showed that the combination of NPs with bioactive principles bestows improved efficiency [12-14]. The present study implicated that the percentage of mosquito larvicidal mortality increased by many folds with the addition of bio-stabilized AgNPs [31]. Similarly, Muthukumaran et al. [20] recently focused on the potential of Gmelina asiatica-mediated synthesis of Ag NPs against A. stephensi, A. aegypti, and C. quinquefasciatus, obtaining higher $\mathrm{LC}_{50}$ values (i.e., 22.44, 25.77, and $27.83 \mu \mathrm{g} / \mathrm{mL}$, respectively). Also, Govindarajan et al. [7] reported that the acute toxicity of Malva sylvestris leaf extract and green-synthesized AgNPs were effective against larvae of the malaria vector $A$. stephensi, the dengue vector $A$. aegypti and the filariasis vector $C$. 


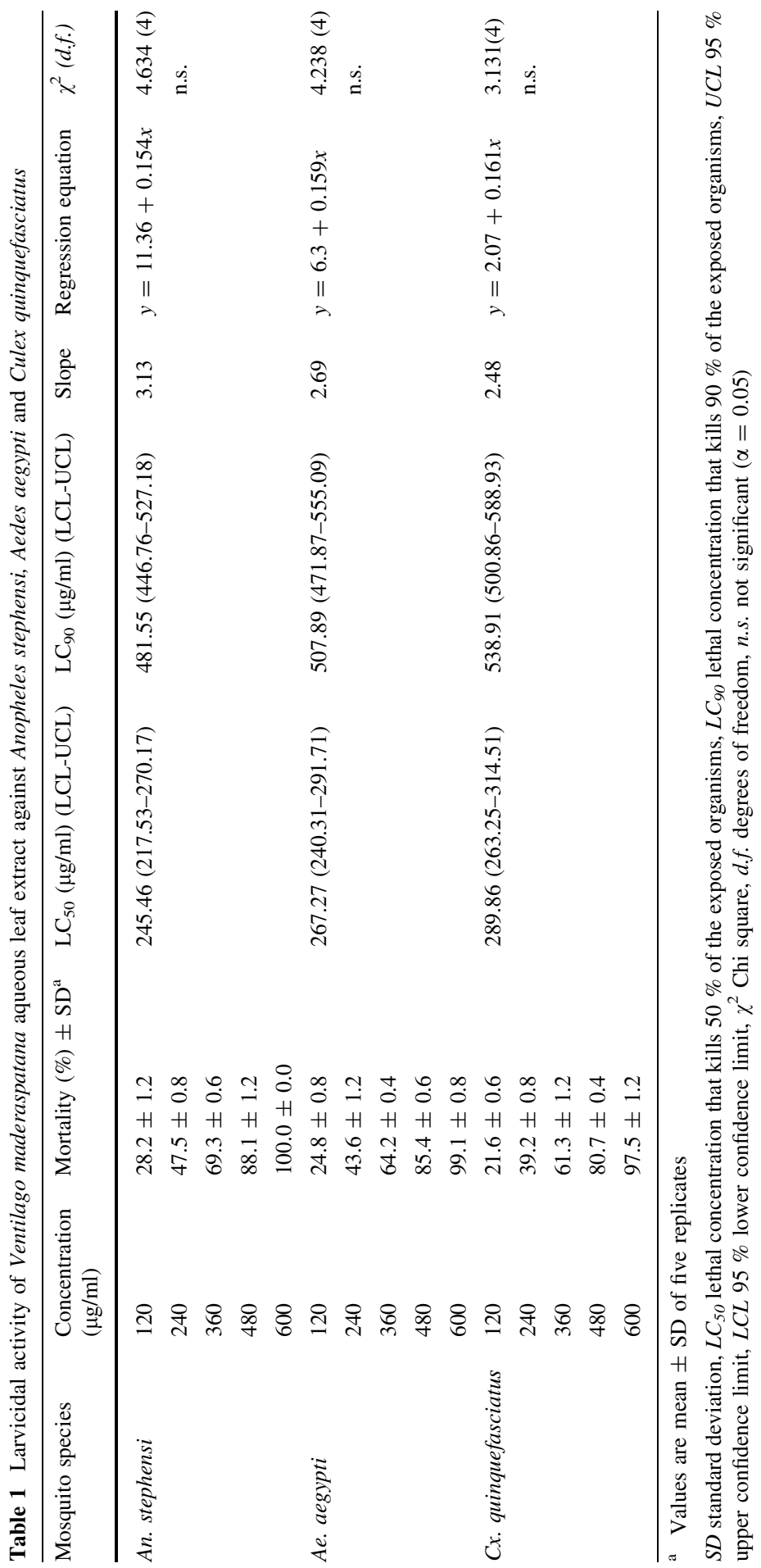




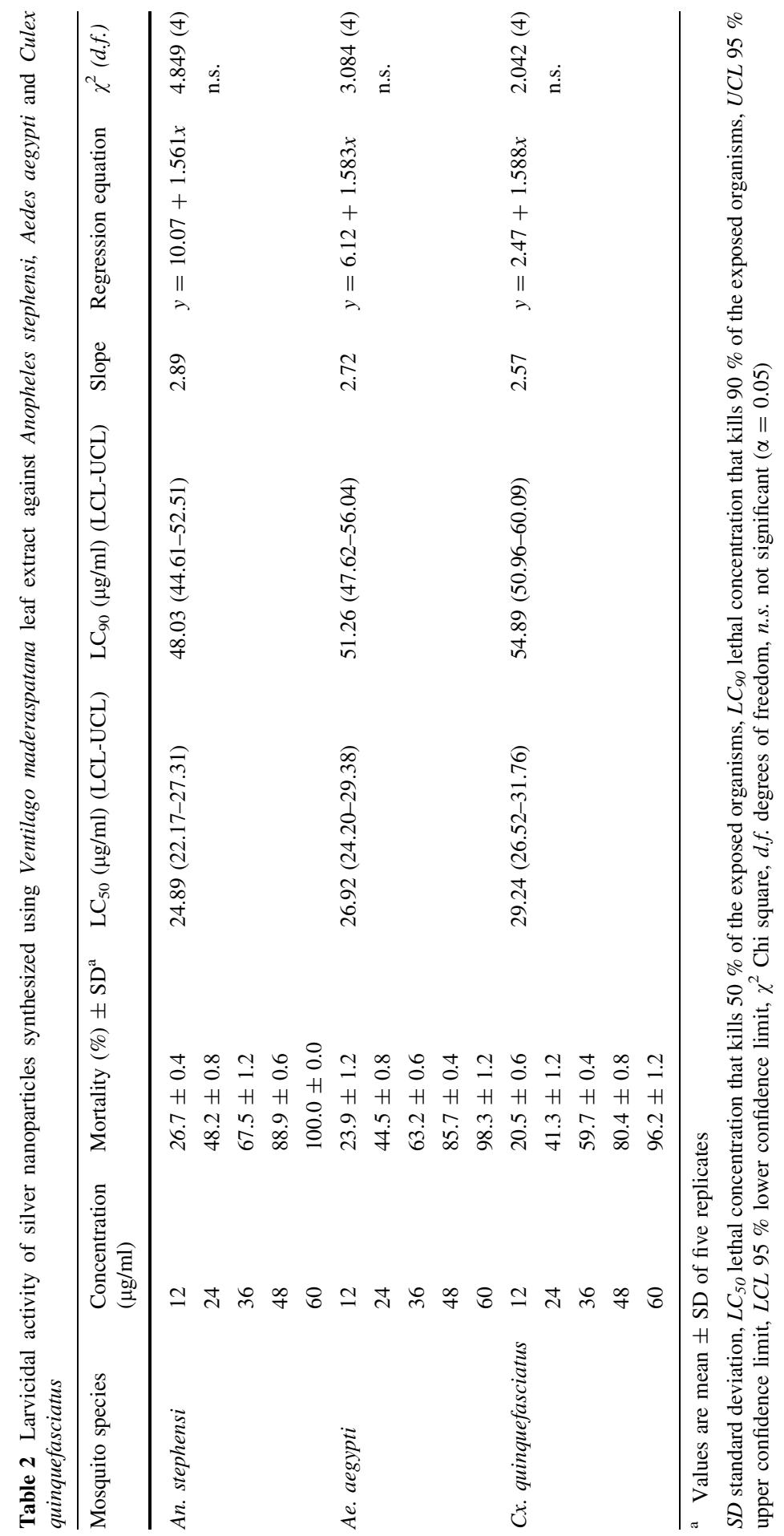




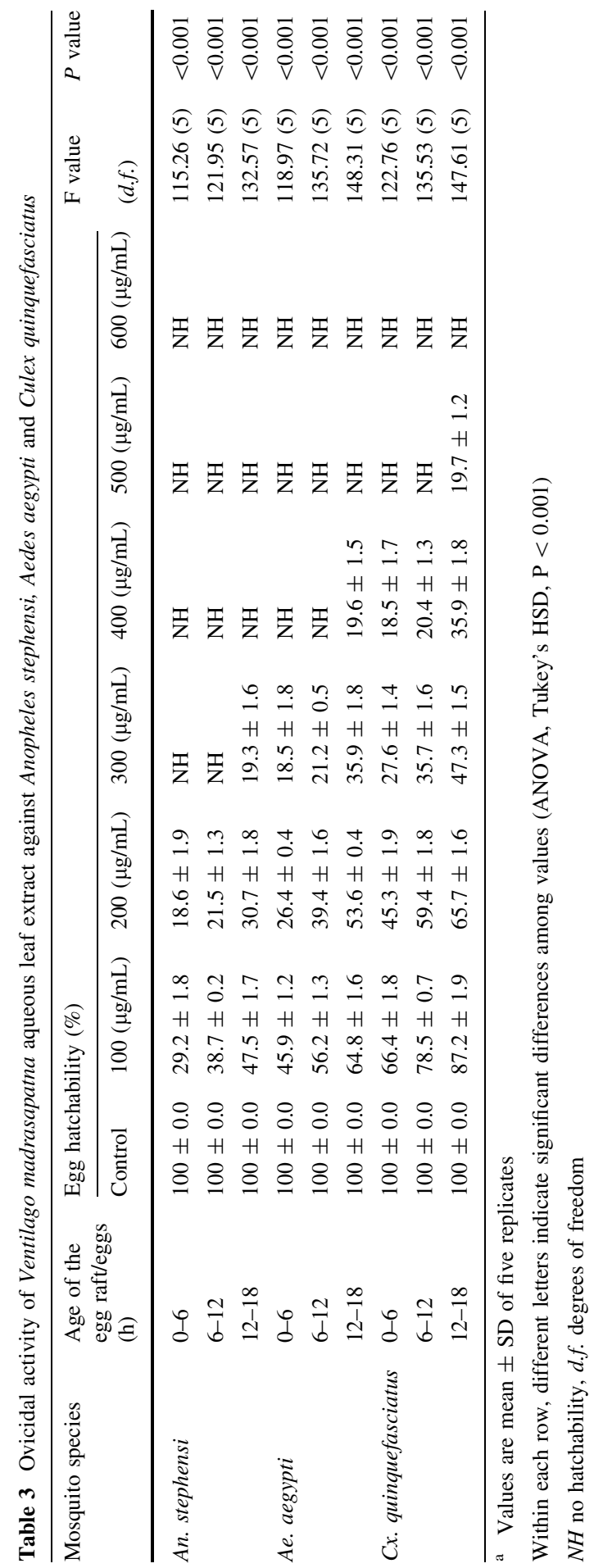




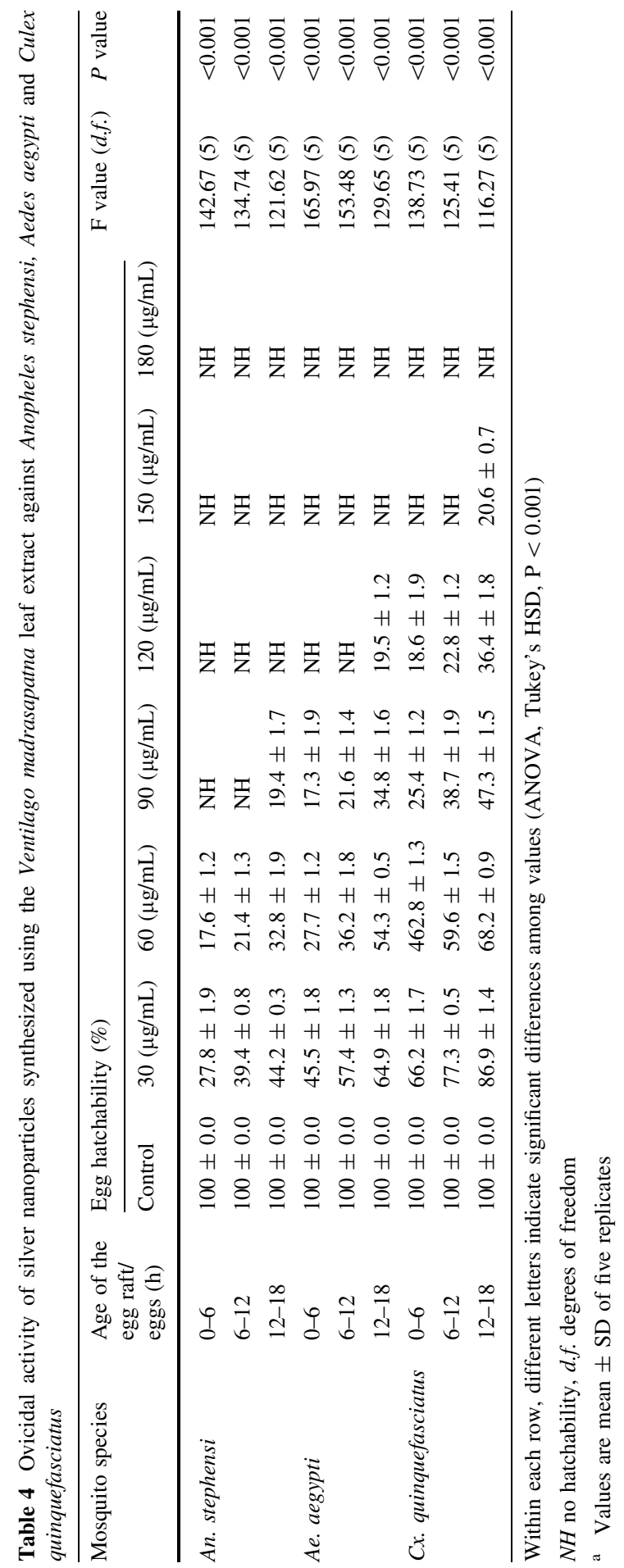




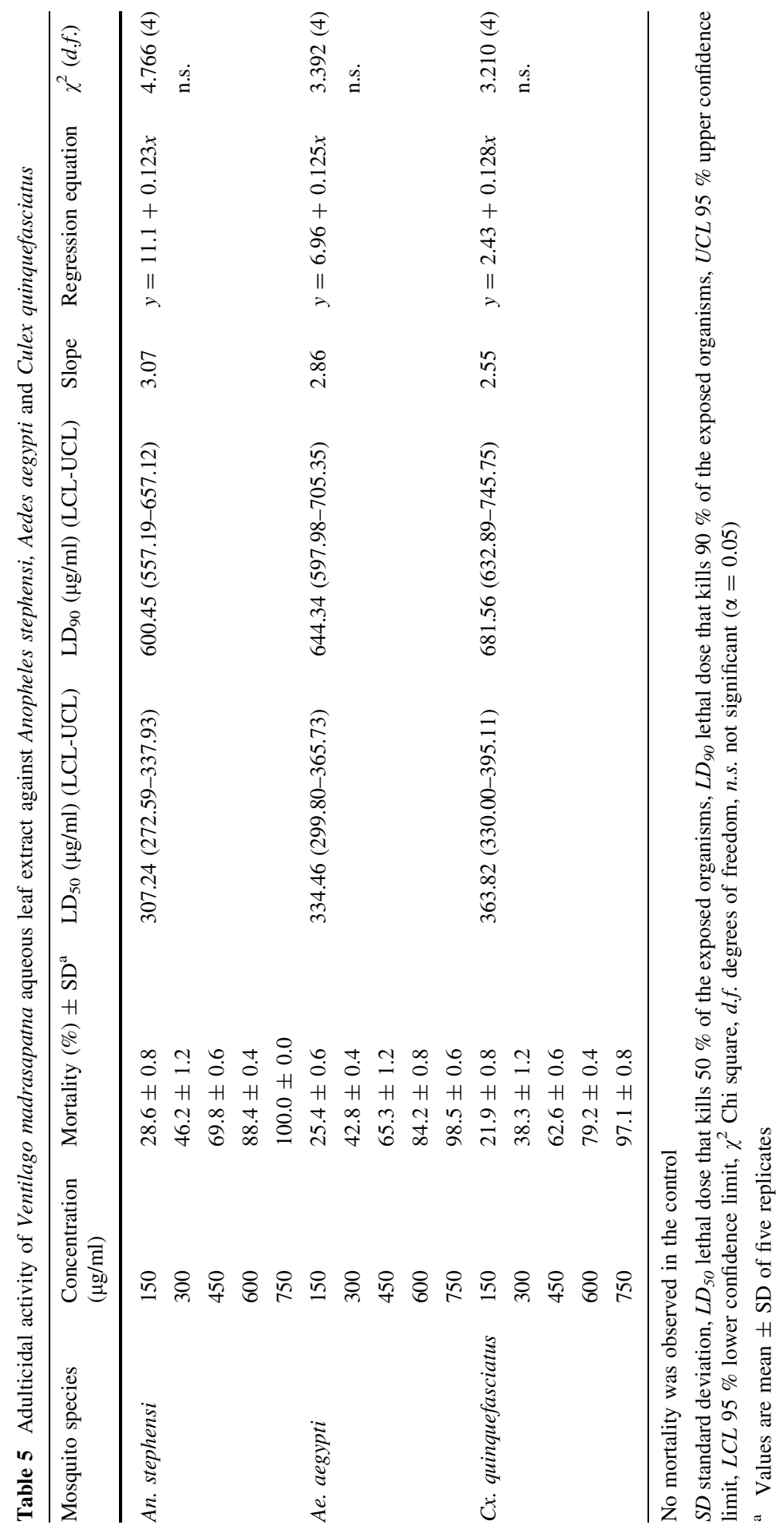




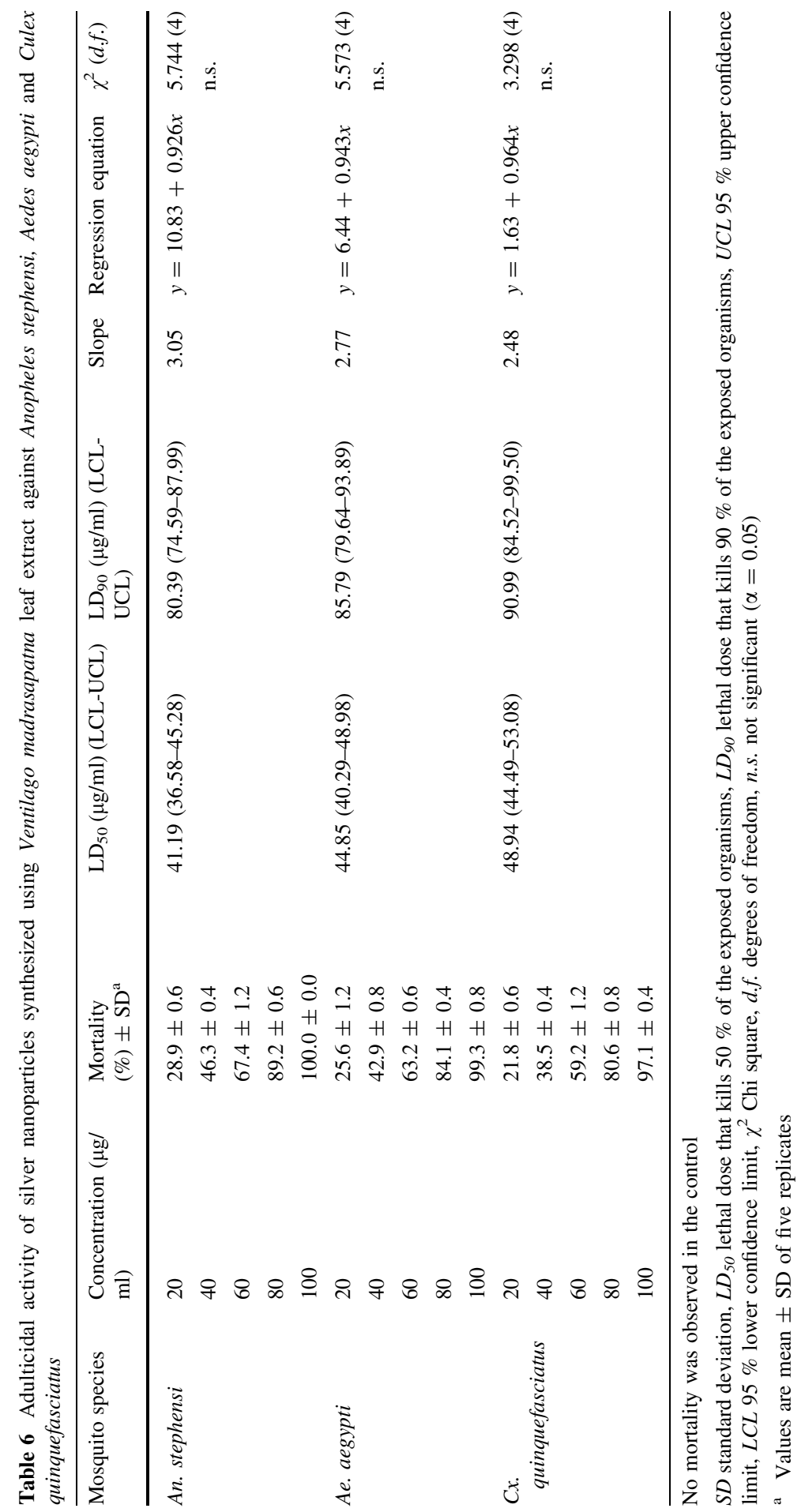


quinquefasciatus. Compared to the leaf aqueous extract, AgNPs showed higher toxicity against $A$. stephensi, $A$. aegypti, and $C$. quinquefasciatus with $\mathrm{LC}_{50}$ values of $10.33,11.23$, and $12.19 \mu \mathrm{g} / \mathrm{mL}$, respectively. The $B$. cristata-synthesized AgNP and aqueous leaf extract showed larvicidal properties against third instar larvae of the mosquito vectors A. subpictus, A. albopictus, and C. tritaeniorhynchus; $\mathrm{LC}_{50}$ values of synthesized AgNPs were 12.46, 13.49, and $15.01 \mu \mathrm{g} / \mathrm{mL}$, respectively and aqueous leaf extract $\mathrm{LC}_{50}$ values were 124.27, 135.32, and $146.31 \mu \mathrm{g} / \mathrm{mL}$, respectively [18]. The acute toxicity of biosynthesized AgNPs with C. spinarum leaf extract was evaluated against larvae of the malaria vector $A$. subpictus, the dengue vector $A$. albopictus and the Japanese encephalitis vector $C$. tritaeniorhynchus; AgNPs showed higher toxicity against A. subpictus, A. albopictus, and $C$. tritaeniorhynchus with $\mathrm{LC}_{50}$ values of $8.37,9.01$ and $10.04 \mu \mathrm{g} / \mathrm{mL}$, respectively [49]. Veerakumar et al. [21] investigated the $F$. elephantumsynthesized silver nanoparticles were toxic against A. stephensi, A. aegypti, and C. quinquefasciatus; A. stephensi had $\mathrm{LC}_{50}$ of $11.56 \mu \mathrm{g} / \mathrm{mL} ; A$. aegypti had $\mathrm{LC}_{50}$ of $13.13 \mu \mathrm{g} / \mathrm{mL}$; and C. quinquefasciatus had $\mathrm{LC}_{50}$ of $14.19 \mu \mathrm{g} / \mathrm{mL}$.

Concerning the mechanism(s) of action, the observed larvicidal activity may be attributed to the interaction between AgNPs and the extracellular lipo-protein matrix. This interaction increases the permeability of the plasma membrane of cells. In addition, the interaction(s) between AgNPs and sulfur-containing proteins or phosphorous containing compound may lead to denaturation of organelles and enzymes, reducing ATP synthesis which finally causes the loss of the cellular function and cell death [13, 50, 51].

\section{Biotoxicity on Non-target Biocontrol Agents}

The biotoxicity of $V$. maderaspatana aqueous extract and green-synthesized AgNPs on non-target biocontrol organisms A. bouvieri, D. indicus and G. affinis. Toxicity treatments achieved negligible toxicity against A. bouvieri, D. indicus and G. affinis, with $\mathrm{LC}_{50}$ values ranging from 1673 to $41,854 \mu \mathrm{g} / \mathrm{ml}$ (Tables 7,8 ). Focal observations highlighted that longevity and swimming activity of the study species were not altered for a week after testing. SI indicated that $V$. maderaspatanafabricated AgNPs were less toxic to the non-target organism tested if compared to the targeted mosquito larval populations (Table 9). Nowadays, limited knowledge is available about the acute toxicity of plant-borne mosquitocides and green-fabricated metal nanoparticles on non-target aquatic species [13]. Recently, the EO of Zanthoxylum monophyllum and its major chemical compounds were found ecofriendly for the predatory fish G. affinis. Given that the $\mathrm{LC}_{50}$ for G. affinis was estimated at $4234.07 \mu \mathrm{g} / \mathrm{mL}$, the EO can be considered completely safe for this fish species, with SI ranging from 86.39 for the least sensitive larvae of $C$. tritaeniorhynchus to 102.02 for the most sensitive larvae of A. subpictus [52]. Furthermore, Govindarajan et al. [7] reported that the biotoxicity of M. sylvestris aqueous extract and green-synthesized AgNPs was negligible also on non-target organisms $D$. indicus and $G$. affinis, since the toxicity treatments achieved $\mathrm{LC}_{50}$ values ranging from 813.16 to $10,459.13 \mu \mathrm{g} / \mathrm{mL}$. Also, the biotoxicity of $B$. cristata aqueous extract and green-synthesized AgNPs was evaluated on non-target 


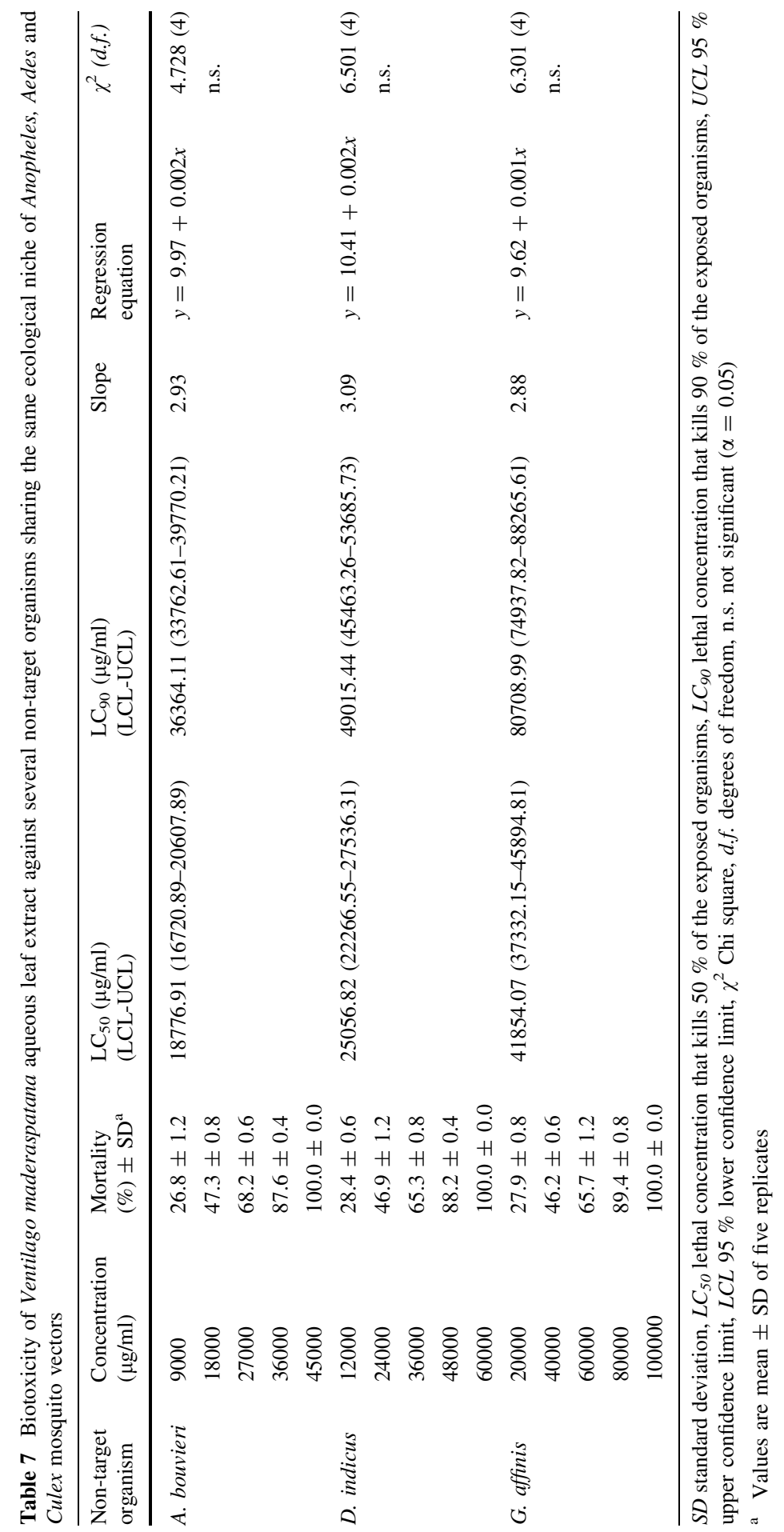




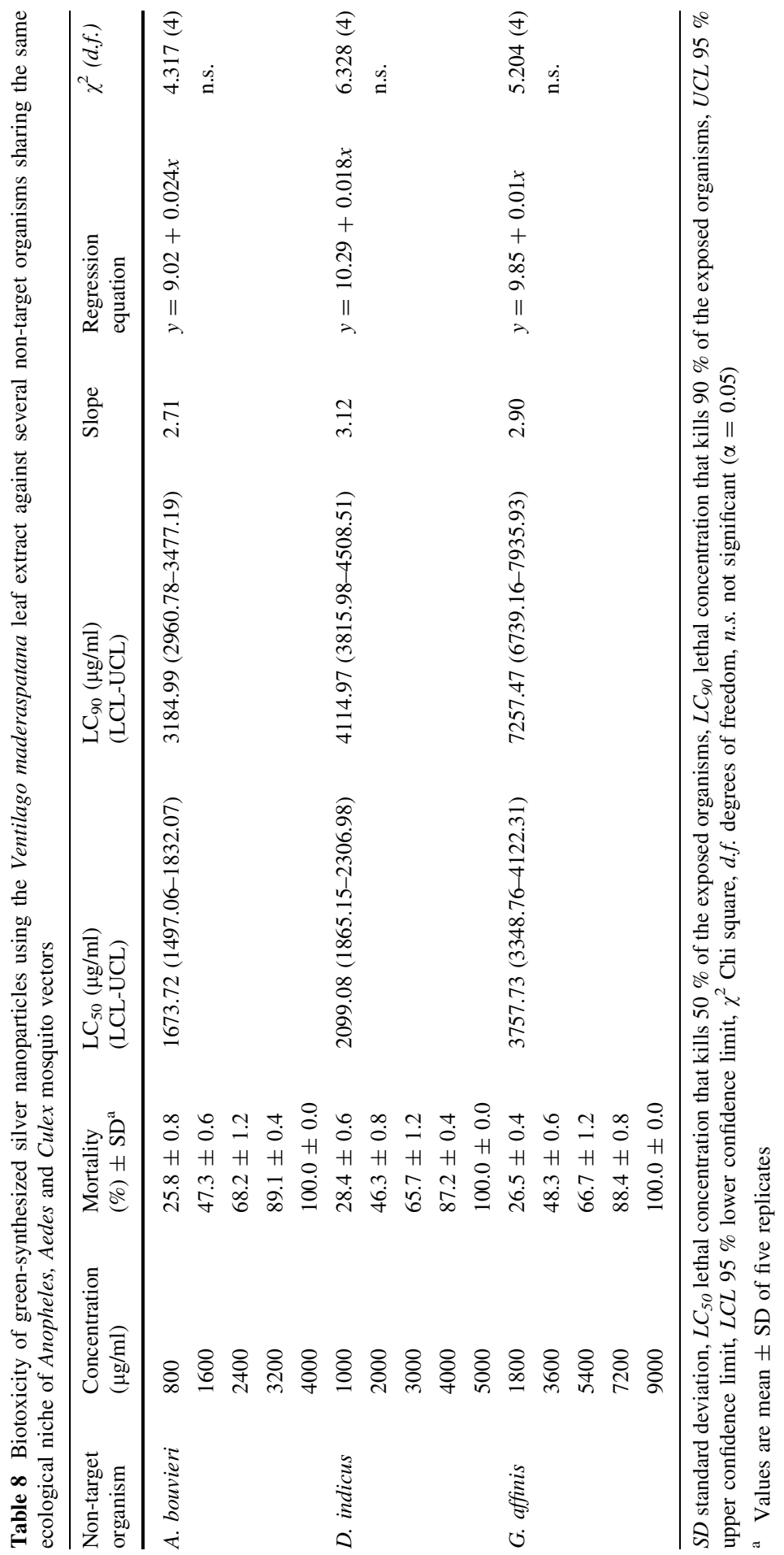


Table 9 Suitability index of different non-target organism over young instars of Anopheles stephensi, Aedes aegypti and Culex quinquefasciatus exposed to Ventilago maderaspatana aqueous leaf extract and green-synthesized silver nanoparticles

\begin{tabular}{lllll}
\hline Treatment & Non-target organism & An.stephensi & Ae.aegypti & Cx.quinquefasciatus \\
\hline Aqueous leaf extract & A. bouvieri & 76.49 & 70.25 & 64.77 \\
& D. indicus & 102.08 & 93.75 & 86.44 \\
& G. affinis & 170.51 & 156.59 & 144.39 \\
Silver nanoparticles & A. bouvieri & 67.24 & 62.17 & 57.24 \\
& D. indicus & 84.33 & 77.97 & 71.78 \\
& G. affinis & 150.97 & 139.58 & 128.51 \\
\hline
\end{tabular}

organisms $D$. indicus, A. bouvieri, and G. affinis with $\mathrm{LC}_{50}$ values ranging from 633.26 to $8595.89 \mu \mathrm{g} / \mathrm{mL}$, respectively [18].

AgNPs biosynthesized using the 2, 7.bis [2-(diethylamino)-ethoxy] fluorence isolate from the Melia azedarach leaves did not show acute toxicity against Mesocyclops pehpeiensis copepods [53]. Moreover, Subarani et al. [54] reported that the $V$. rosea-synthesized silver nanoparticles did not exhibit any noticeable toxicity on $P$. reticulata after 24,48 , and 72 h of exposure. These results suggest that the synthesized AgNPs have the potential to be used as an ideal eco-friendly approach for the control of the A. aegypti larvae. Lastly, the biotoxicity of $C$. spinarum aqueous extract and green-synthesized AgNPs on non-target organisms $D$. indicus, A. bouvieri and G. affinis. Toxicity treatments achieved negligible toxicity with $\mathrm{LC}_{50}$ values ranging from 424.09 to $6402.68 \mu \mathrm{g} / \mathrm{mL}$. Concerning sub-lethal effects, G. affinis exposed to nanoparticle-contaminated aquatic environments showed higher predation rates against both A. stephensi and A. albopictus larvae [49].

\section{Conclusions}

In conclusion, AgNPs were rapidly biosynthesized at room temperature using a cheap $V$. maderaspatana leaf extract. Bio-reduced silver nanocrystals were polydispersed and stable in solution for at least four weeks. AgNPs have excellent antimosquito larvicidal activity against third instar larvae of three important mosquito vectors, with $\mathrm{LC}_{50}$ values ranging from 24.89 to $29.24 \mu \mathrm{g} / \mathrm{mL}$. The prospect of utilizing natural products for synthesizing silver nanoparticles and testing their efficacy in controlling mosquitoes as larvicides is a recent phenomenon facilitating the development of more potent and environmentally safe pesticides. Overall, this $V$. maderaspatana-based route of nanosynthesis may be considered for the development of newer and safer mosquito larvicides to be used against neglected vectors of arbovirus in tropical and subtropical countries worldwide. 
Acknowledgments Three anonymous reviewers improved an earlier version of the manuscript. The authors are thankful to the Principal and Head of the Department of Zoology, Khadir Mohideen College for the facilities provided to carry out this work. The authors would like to thank Professor and Head, Department of Zoology, Annamalai University for the laboratory facilities provided. The authors would also like to acknowledge the cooperation of staff members of the VCRC (ICMR), Pondicherry.

\section{Compliance with ethical standards}

Conflicts of interest The Authors declare no conflicts of interest.

Human and Animal Rights All applicable international and national guidelines for the care and use of animals were followed. All procedures performed in studies involving animals were in accordance with the ethical standards of the institution or practice at which the studies were conducted.

\section{References}

1. G. Benelli (2015). Parasitol. Res. 114, 2801-2805.

2. G. Benelli (2015). Parasitol. Res. 114, 3201-3212.

3. R. Pavela (2015). Ind. Crops Prod. 76, 174-187.

4. R. Pavela (2015). Ind. Crops Prod. 30, 311-315.

5. M. Govindarajan, M. Rajeswary, S. L. Hoti, K. Murugan, K. Kovendan, S. Arivoli, and G. Benelli (2016). J. Asia Pac. Entomol. 19, 51-58.

6. M. Govindarajan, M. Rajeswary, K. Veerakumar, S. L. Hoti, H. Mehlhorn, D. R. Barnard, and G. Benelli (2016). Parasitol. Res. 115, 723-733.

7. M. Govindarajan, S. L. Hoti, M. Rajeswary, and G. Benelli (2016). Parasitol. Res. 115, 2685-2695.

8. K. Yokohama and D. R. Welchons (2007). Nanotechnology 18, 105101-105107.

9. V. K. Sharma, R. A. Yngard, and Y. Lin (2009). Adv. Colloid. Interf. Sci. 145, 83-96.

10. J. Y. Song and B. S. Kim (2009). Bioprocess. Biosyst. Eng. 32, 79-84.

11. S. S. Shankar, A. Rai, B. Ankamwar, A. Singh, A. Ahmad, and M. Sastry (2004). Nat. Mater. 3, 482-488.

12. G. Benelli (2016). Parasitol. Res. 115, 23-34.

13. G. Benelli in H. Mehlhorn (ed.), Plant-synthesized nanoparticles in the fight against mosquito vectors: an eco-friendly tool against mosquito vectors (Springer, New York, 2016), p. 155.

14. G. Benelli (2016). Asian Pac. J. Trop. Biomed. 6, 353-354.

15. J. Huang, Q. Li, and D. Sun (2007). Nanotechnology 18, 105104.

16. H. Salam, A. Rajiv, P. Kamaraj, M. Jagadeeswaran, P. Sangeetha, S. Gunalan, and R. Sivaraj (2012). Int. Res. J. Biol. Sci. 1, 85-90.

17. K. Veerekumar, M. Govindarajan, and M. Rajeswary (2013). Parasitol. Res. 112, 4073-4085.

18. M. Govindarajan and G. Benelli (2016). Parasitol. Res. 115, 925-935.

19. U. Muthukumaran, M. Govindarajan, and M. Rajeswary (2015). Parasitol. Res. 114, 989-999.

20. U. Muthukumaran, M. Govindarajan, and M. Rajeswary (2015). Parasitol. Res. 114, 1817-1827.

21. K. Veerakumar, M. Govindarajan, M. Rajeswary, and U. Muthukumaran (2014). Parasitol. Res. 113, 1775-1785.

22. K. Veerakumar, M. Govindarajan, M. Rajeswary, and U. Muthukumaran (2014). Parasitol. Res. 113, 2363-2373.

23. C. D. Patil, H. P. Borase, S. V. Patil, R. B. Salunkhe, and B. K. Salunke (2012). Parasitol. Res. 111, 555-562.

24. C. D. Patil, S. V. Patil, H. P. Borase, B. K. Salunke, and R. B. Salunkhe (2012). Parasitol. Res. 110, 1815-1822.

25. R. N. Chopra, S. L. Nayar, and I. C. Chopra Glossary of Indian Medicinal Plants (New Delhi, CSIR, 1956).

26. G. N. Krishnakumari, B. Bhuvaneswari, and I. R. Swapna (2001). Fitoterapia 72, 671-675.

27. B. K. Rao, T. Hanumaiah, C. P. Rao, G. S. R. Rao, K. V. J. Rao, and R. H. Thomson (1983). Phytochemistry 22, 2583-2585.

28. S. Basu, A. Ghosh, and B. Hazra (2005). Phytother. Res. 19, 888-894. 
29. N. Duganath, S. R. Kumar, R. Kumanan, and K. N. Jayaveera (2010). IJPBS 1, 1-7.

30. S. Ghosh, M. D. Sarma, A. Patra, and B. Hazra (2010). J. Pharm. Pharmacol. 62, 1158-1166.

31. M. Govindarajan and G. Benelli (2016). RSC Adv. 6, 59021-59029.

32. World Health Organization (2005). WHO, Geneva, HO/CDS/WHOPES/GCDPP/1.3.

33. T. Su and M. S. Mulla (1998). J. Am. Mosq. Control Assoc. 14, 204.

34. M. Govindarajan, A. Jebanesan, and T. Pushpanathan (2008). Parasitol. Res. 102, 289.

35. World Health Organization (1981). WHO, Geneva, WHO/VBC/81.806.

36. N. Sivagnaname and M. Kalyanasundaram (2004). Mem. Inst. Oswaldo Cruz. 99, 115-118.

37. M. Govindarajan and G. Benelli (2016). J. Clust. Sci. doi:10.1007/s10876-016-1035-6.

38. D. J. Finney Probit Analysis (Cambridge University Press, London, 1971), pp. 68-72.

39. P. G. Deo, S. B. Hasan, and S. K. Majumdar (1988). Int. Pest Control. 30, 118-129.

40. V. Gopinath and P. Velusamy (2013). Spectrochim. Acta A 106, 170-174.

41. N. Muniyappan and N. S. Nagarajan (2014). Proc. Biochem. 49, 1054-1061.

42. M. Govindarajan, M. Rajeswary, K. Veerakumar, U. Muthukumaran, S. L. Hoti, and G. Benelli (2016). Exp. Parasitol. 161, 40-47.

43. V. Gopinath, D. MubarakAli, S. Priyadarshini, N. M. Priyadharsshini, N. Thajuddin, and P. Velusamy (2012). Colloids Surf. B 96, 69-74.

44. R. Sanghi and P. Verma (2009). Biores. Technol. 100, 501-504.

45. S. Shivshankar, A. Ahmad, and M. Sastry (2003). Biotechnol. Prog. 19, 1627-1631.

46. G. Angajala, R. Ramya, and R. Subashini (2014). Acta. Tropica. 135, 19-26.

47. P. Magudapatty, P. Gangopadhyayransm, B. K. Panigrahi, K. G. M. Nair, and S. Dhara (2001). Physica B 299, 142-146.

48. V. Vignesh, K. F. Anbarasi, S. Karthikeyeni, G. Sathiyanarayanan, P. Subramaniana, and R. Thirumurugan (2013). Colloid Surf. A 439, 184-192.

49. M. Govindarajan, M. Nicoletti, and G. Benelli (2016). J. Clust. Sci. 27, 745-761.

50. N. Sap-Iam, C. Homklinchan, R. Larpudomlert, W. Warisnoicharoen, A. Sereemaspun, and S. Dubas (2010). J. Appl. Sci. 10, 3132-3136.

51. I. Sondi and B. Salopek-Sondi (2004). J. colloid Interface Sci. 275, 177-182.

52. R. Pavela and M. Govindarajan (2016). J. Pest Sci. doi:10.1007/s10340-016-0763-6.

53. R. Ramanibai and K. Velayutham (2015). Res. Vet. Sci. 98, 82-88.

54. S. Subarani, S. Sabhanayakam, and C. Kamaraj (2013). Parasitol. Res. 112, 487-499. 